University of South Carolina

Scholar Commons

\title{
Developing a Robust Geologic Conceptual Model Using Pseudo 3-D P-Wave Seismic Reflection Data
}

\author{
Adrian Addison \\ University of South Carolina - Columbia \\ Michael G. Waddell \\ University of South Carolina - Columbia \\ Camelia C. Knapp \\ University of South Carolina - Columbia, camelia@geol.sc.edu \\ Duke T. Brantley \\ University of South Carolina - Columbia \\ John M. Shafer \\ University of South Carolina - Columbia
}

Follow this and additional works at: https://scholarcommons.sc.edu/geol_facpub

Part of the Earth Sciences Commons

\section{Publication Info \\ Published in Environmental Geosciences, Volume 16, Issue 1, 2009, pages 41-56.}

Addison, A. D., Waddell, M. G., Knapp, C. C., Brantley, D. T., \& Shafer, J. M. (2009). Developing a robust geologic conceptual model using pseudo 3-D P-wave seismic reflection data. Environmental Geosciences, $16(1), 41-56$.

CEnvironmental Geosciences 2009, The American Association of Petroleum Geologists/Division of Environmental Geosciences

This Article is brought to you by the Earth, Ocean and Environment, School of the at Scholar Commons. It has been accepted for inclusion in Faculty Publications by an authorized administrator of Scholar Commons. For more information, please contact digres@mailbox.sc.edu. 
Developing a robust geologic conceptual model using pseudo 3-D P-wave
seismic reflection data

\author{
Adrian D. Addison, Michael G. Waddell, \\ Camelia C. Knapp, Duke T. Brantley, and John M. Shafer
}

\begin{abstract}
As part of a multiscale hydrogeophysical and modeling study, a pseudo three-dimensional (3-D) seismic survey was conducted over a contaminant plume at $\mathrm{P}$ area, Savannah River site (South Carolina), to enhance the existing geologic model by resolving uncertainties in the lithostratigraphic sequence. The geometry of the dissolved phase trichloroethylene plume, based on initial site characterization, appears to be confined to a narrow corridor within the Eocene sand overlying a clay unit approximately $25 \mathrm{~m}(82 \mathrm{ft})$ below land surface. Processing the seismic data as a 3-D data volume instead of a series of closely spaced two-dimensional lines allowed for better interpretation of the target horizons, the lower clay, and the sand above the clay. Calibrating the seismic data with existing borehole geophysical logs, core data as well as vertical seismic profiling (VSP) data allowed the seismic data to be inverted from two-way traveltime to depth, thereby facilitating full integration of the seismic data into a solid earth model that is the basic part of a site conceptual model. The outcome was the production of realistic horizon surface maps that show that two channel complexes are located on the section, which are not present in the conceptual model, and that the upper and middle clays are not laterally continuous as previously thought. The geometry of the primary channel has been transposed over the map view of the plume to investigate potential relationships between the shape of the plume and the presence of the channel.
\end{abstract}

\section{INTRODUCTION}

The $\mathrm{P}$ area at the Savannah River site (SRS) is located in the upper Atlantic coastal plain of South Carolina (Figure 1), which consists of approximately $350 \mathrm{~m}$ (1148 ft) of unconsolidated sands, clays, and

Copyright (C)2009. The American Association of Petroleum Geologists/Division of Environmental Geosciences. All rights reserved.

DOI:10.1306/eg.10210808005

\section{AUTHORS}

AdRIAN D. AdDIson Department of Geological Sciences, University of South Carolina, Columbia, South Carolina; aaddison@geol.sc.edu

Adrian Addison is a Ph.D. candidate in the Department of Geological Sciences at the University of South Carolina. He received his B.S. degree in geophysics from the University of Oklahoma and worked for 4 years as a geophysicist with the U.S. Geological Survey. His research interests are borehole and nearsurface geophysics, environmental geology, and signal processing.

MiCHAEL G. WADDELL Earth Sciences and Resources Institute, University of South Carolina, ESRI-USC Columbia, South Carolina

Michael Waddell completed his graduate studies at ESRI-USC in 1982 and remained at ESRI-USC until 1984 when he became a reservoir geologist in Houston working on petrographic investigations of hydrocarbon reservoirs worldwide. In 1986, he returned to ESRI-USC to start an environmental geophysics group and is presently its manager.

CAMELIA C. KNAPP $\sim$ Department of Geological Sciences, University of South Carolina, Columbia, South Carolina

Camelia Knapp received her Ph.D. in geophysics from Cornell University and her B.S. and M.S. degrees in geophysical engineering from the University of Bucharest (Romania). She worked with the Romanian State Oil Company and the National Institute for Earth Physics. Currently at the University of South Carolina, her research interests include exploration and environmental geophysics, crustalscale seismology, and gas hydrates.

DUKE T. BRANTLEY Earth Sciences and Resources Institute, University of South Carolina, Columbia, South Carolina

Duke Brantley is an M.S. degree candidate in the Department of Geological Sciences at the University of South Carolina. He received his M.S. degree in earth and environmental resources management from the University of South Carolina in 2006. He provides field and analytical support for geophysical and dewatering 
studies for the Earth Sciences and Resources Institute at the University of South Carolina.

JOHN M. SHAFER Earth Sciences and Resources Institute, University of South Carolina, Columbia, South Carolina

John Shafer earned his Ph.D. in civil engineering from Colorado State University, his M.S. degree in resource development from Michigan State University, and his B.S. degree in earth science from Penn State University. His research focus includes integrated site characterization, coupled simulation-optimization approaches to solving groundwater problems, and groundwater susceptibility and contamination potential analysis.

\section{ACKNOWLEDGEMENTS}

We would like to thank Maggie Millings (Savannah River National Laboratory) for her contributions in the completion of this work. We would like to thank Mary Harris and Gregory Flach (Savannah River National Laboratory), Susan Hubbard (Lawrence Berkeley National Laboratory), and Antonio Cameron (Geophysical Exploration Laboratory, University of South Carolina) for their contributions on the project. We would also like to thank Landmark Graphic Corporation and Seismic Micro-Technology, Inc. (ProMAX ${ }^{\mathbb{R}}$ and Kingdom ${ }^{\mathbb{R}}$ Suite software packages) for the University Grants Programs. This work was made possible through a grant by the U. S. Department of Energy (grant DEOFG02-06ER64210). gravels ranging in age from Cretaceous to Pleistocene (Fallaw and Price, 1995) (Figure 2). Precharacterization efforts revealed that the groundwater is primarily contaminated with volatile organic compounds and tritium. Several plumes have been identified, and the plume of interest is a trichloroethylene (TCE) plume that emanates from the northwest section of the reactor facility and discharges to nearby Steel Creek (Figure 3). According to Millings et al. (2003), organic solvents, such as TCE, used in P-reactor operations were disposed of onsite. The shallow geological environment of the $\mathrm{P}$ area has been modestly characterized via a limited number of cone penetrometer (CPT) pushes and the installation of several clusters of observation wells.

This study is confined to the upper $45 \mathrm{~m}(148 \mathrm{ft})$ of Miocene and upper Eocene age coastal plain sediments. Figure 2 shows a simplified stratigraphic column of the units of interest starting from the surface with the upper sand unit followed by the upper clay, middle sand, middle clay, lower sand, and lower clay units. At $\mathrm{P}$ area, the TCE plume is located in an Eocene age sand that lies between the upper clay and middle clay units of the upper Atlantic coastal plain sediments (Figure 2). The geometry of the plume, based on initial site characterization from well, core, and CPT data, appears to be confined to a narrow corridor of sand overlying the middle clay unit

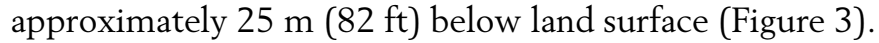

In 2006, three additional wells were installed at the site as part of a multiscale hydrogeophysical and modeling study where the TCE was identified below the middle clay. As part of an ongoing study at the $\mathrm{P}$ area, a pseudo three-dimensional (3-D) P-wave seismic survey was performed at the site. The seismic survey area was 34 by $170 \mathrm{~m}$ $(111$ by $558 \mathrm{ft}$ ), and 2906 shot points were recorded. Processing the data set as a 3-D data volume instead of a series of closely spaced 2-D lines allowed for better interpretation of the target horizons, which are the lower clay and the sand directly above it.

Traditional two-dimensional (2-D) common depth point (CDP) seismic surveys consist of acquiring a single shot and receiver line that is a single slice of the subsurface. The CDP method involves designing the seismic survey such that multiple ray paths are recorded from the same subsurface reflection point. This redundancy allows for determination of the subsurface velocity structure and the cancellation of certain types of extraneous seismic waves and random noise (Yilmaz, 1987). The pseudo 3-D reflection survey was designed to image the top of the first aquitard. The depth of this unit at P-area ranges from 21 to $37 \mathrm{~m}$ (69 to $121 \mathrm{ft}$ ) below land surface. Instead of conducting a true 3-D seismic survey, we conducted a CDP swath survey. A true 3-D seismic or patch shooting uses multiple sets of perpendicular source and geophone lines that are arranged in a rectangular pattern (Sheriff and Geldart, 1995). Similar to 2-D CDP acquisition, the swath technique differs from the patch in that several parallel geophone lines are used with (in our case) one source unit in a roll-along fashion (Sheriff and Geldart, 1995). The advantage of the swath for this project is that it achieved the fold multiplicity (the number of times a reflecting point is sampled over 


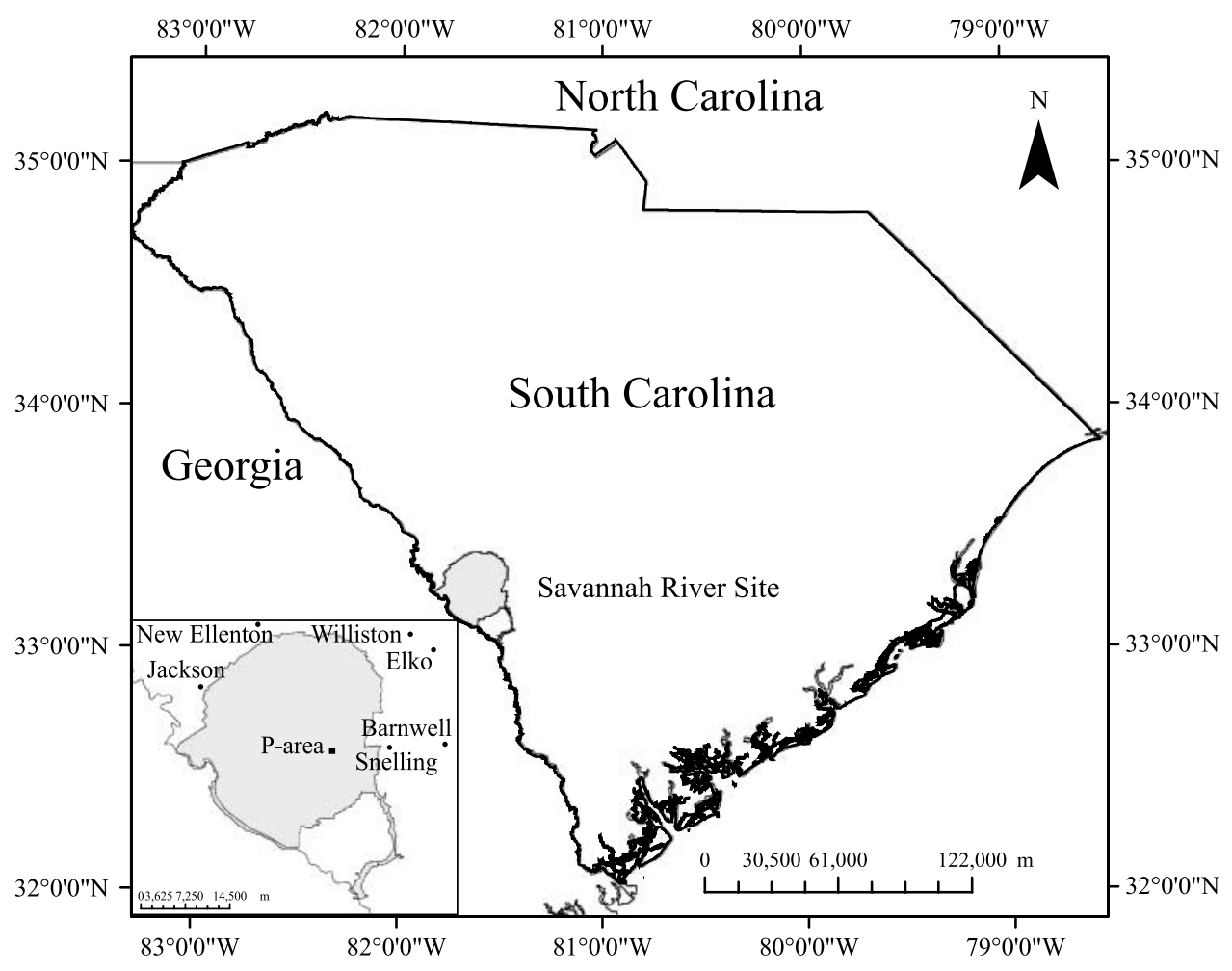

Figure 1. Location of the $P$ area at the Savannah River site, South Carolina.

a spread length) (Sheriff and Geldart, 1995) as the patch technique but in a shorter time and ultimately at lower costs.

In site characterization, a conceptual model is the hydrologists' or geologists' idea of the subsurface (Reilly and Harbaugh, 2004) and is the foundation for building the rest of the models such as the geologic and hydrogeological transport for a particular project. A conceptual model is commonly a simple idea; in the case of the $\mathrm{P}$ area, the conceptual model is a 2-D geologic cross

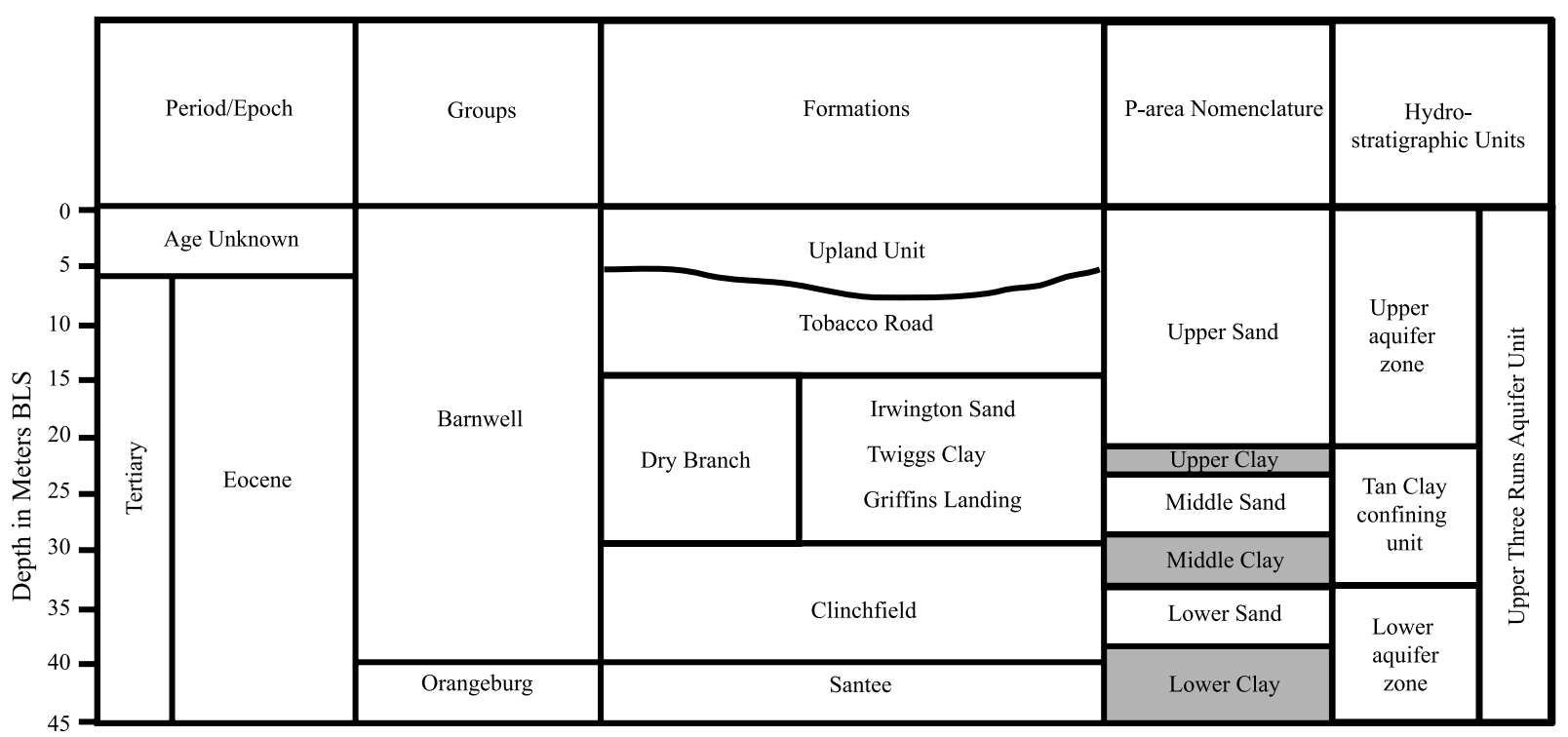

Figure 2. Simplified stratigraphic column for the $P$ area, modified from Fallaw and Price (1995) with hydrostratigraphic units from Aadland et al., 1995. 
Figure 3. Geometry of trichloroethylene (TCE) plume at the $\mathrm{P}$ area, Savannah River site, South Carolina. The vertical seismic profiles (VSPs) were collected in the three position (POS) wells. The red dashed line is an outline of the seismic survey area. Plume flows from east to west discharging into Steel Creek, which is just west of the study area. Plume concentrations were determined from the cone penetrometer (CPT) well data (red triangles) with little well coverage west of the survey.

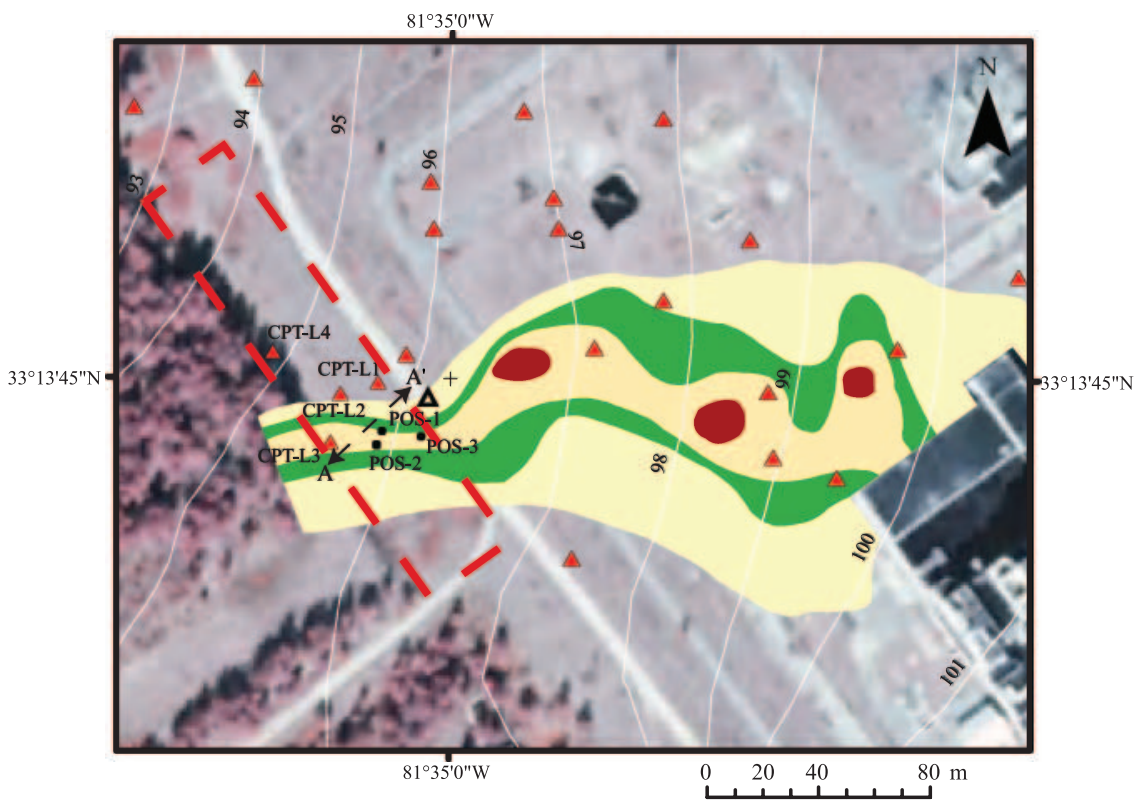

\begin{tabular}{|c|c|c|}
\hline - & $\begin{array}{l}\text { Legend } \\
\text { POS wells (VSPs) }\end{array}$ & $\begin{array}{l}\text { TCE } \\
\text { concentration }\end{array}$ \\
\hline$\Delta$ & CPT wells & \\
\hline$\Delta$ & СРT-PGCPT29 & $10,000 \mu \mathrm{g} / \mathrm{L}$ \\
\hline & Seismic survey area & $1000 \mu \mathrm{g} / \mathrm{L}$ \\
\hline & Cross section & $100 \mu \mathrm{g} / \mathrm{L}$ \\
\hline$\square$ & Contour (1 m) & $5 \mu \mathrm{g} / \mathrm{L}$ \\
\hline
\end{tabular}

\section{HYDROGEOLOGIC SETTING}

The $P$ area at SRS is located in the upper Atlantic coastal plain, which consists of stratigraphy of Upper Cretaceous and Tertiary age sediments. Previous work on the geologic characterization at SRS includes a thorough study by Fallaw and Price (1995). Based on the scope of this project, the Tertiary sediments, which include the middle Eocene age Orangeburg and upper Eocene age Barnwell groups (Fallaw and Price, 1995), will be the focus of this article. The Congaree, Warley Hill, and Santee formations make up the Orangeburg Group, whereas the Barnwell Group consists of the Clinchfield, Dry Branch, and Tobacco Road Sand formations (Jean et al., 2002).

The Clinchfield Formation, a medium-grained, wellsorted, poorly consolidated, large bedded quartz sand is the lowermost formation in the Barnwell Group (Jean et al., 2002). The middle unit of the Barnwell Group, the Dry Branch Formation, is divided into three lithofacies: the Twiggs Clay (marine clay), the Irwinton Sand (sand and clay), and the Griffins Landing Member (calcareous and fossilierous sand) (Jean et al., 2002). 


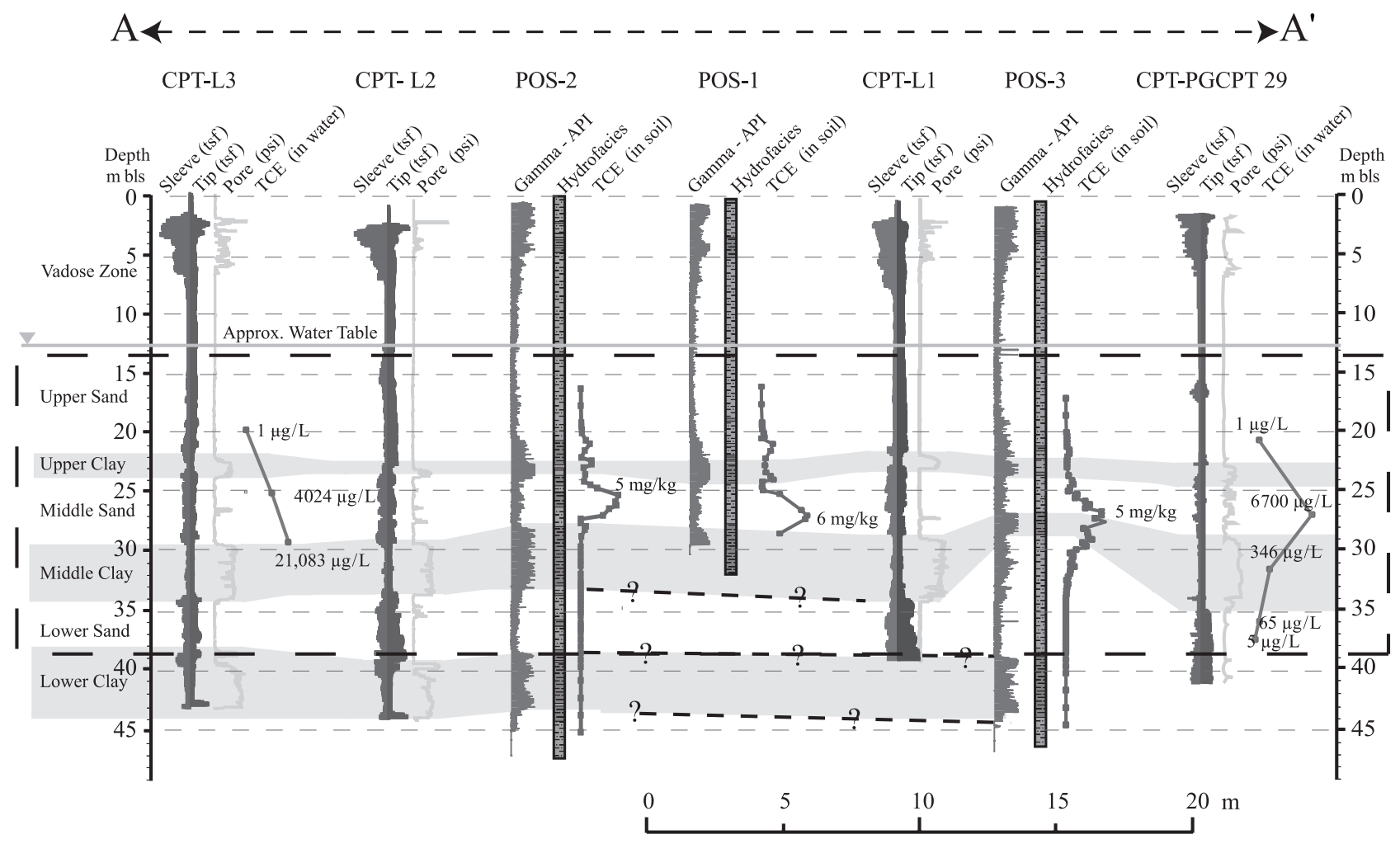

Figure 4. Stratigraphic cross section showing the three clay units and associated sand units at the P-area site. Cores from the position (POS) wells contain gravels above and below the upper clay unit. The dashed rectangle indicates the area of interest. The cross section was provided by the Savannah River National Laboratory. The cross section in the figure was created from cone penetrometer (CPT) data such as sleeve friction, tip friction, and pore pressure while determining the hydrofacies using grain size analysis from core data. TCE = trichloroethylene; BLS = below the surface.

According to Jean et al. (2002), the Tobacco Road Sand lies atop the Barnwell Group and consists of fine-grained and well-sorted to poorly sorted sediments with clay lenses (Jean et al., 2002). Throughout SRS, the "Upland" unit sits atop the Tobacco Road Sand, commonly at higher elevations. The Upland unit is generally thought to have been deposited in a fluvial environment consisting of poorly sorted, silty, clayey, and pebbly sand (Fallaw and Price, 1995).

The hydrogeologic setting at $\mathrm{P}$ area involves the upper part of the Floridan aquifer system that includes the Upper Three Runs aquifer (UTRA) (Aadland et al., 1995). The UTRA includes the Upland unit, Tobacco Road Sand, Dry Branch Formation, Clinchfield Formation, and Santee Limestone. At $\mathrm{P}$ area, the UTRA is informally divided in lower and upper aquifer zones (UAZs) separated by the Tan Clay confining zone (TCCZ). For the purpose of this article, the UTRA has been divided into three zones; the UAZ, the TCCZ, and the lower aquifer zone (LAZ) (Aadland et al., 1995). The LAZ is divided into the lower clay and lower sand facies beneath the TCCZ (Wyatt, 2000). The TCCZ was di- vided in the upper clay, middle sand, and middle clay facies. The UAZ is characterized by massive beds of sand and clayey sand with minor interbeds of clay (Wyatt, 2000).

\section{DATA ACQUISITION}

Before the pseudo 3-D seismic reflection survey was conducted, the minimum and maximum receiver line and source line offsets were determined after a vertical seismic profiling (VSP) analysis of the zero-offset VSP surveys. Zero-offset P-wave vertical seismic profiles were acquired in two wells previously constructed at the site for preliminary hydrogeologic and contaminant distribution characterization. These wells extend through the first aquitard to approximately 30-45 m (98-148 ft) below land surface. Data from the VSP surveys were used to evaluate the vertical acoustic velocity profile at the study site for optimal design of the 3-D surface seismic survey. The zero-offset VSP analysis was performed to determine the source and receiver 
Table 1. Acquisition Parameters for the 3-D Seismic Data Collection at P Area, Savannah River Site, South Carolina

\begin{tabular}{lc}
\hline Parameter & Values \\
\hline Group spacing & $1 \mathrm{~m}$ \\
Line spacing & $2 \mathrm{~m}$ \\
Sample rate & $0.5 \mathrm{~ms}$ \\
Record length & $500 \mathrm{~ms}$ \\
Accelerated weight drop & $4-6$ stacks per shot \\
Total shots & 2906 \\
\hline
\end{tabular}

line minimum and maximum offset as well as the source and receiver spacing and sample rate. This provided detailed information on lateral and vertical stratigraphic heterogeneity, subsurface velocities, and noise and signal attenuation. These data were necessary to design the acquisition parameters for the 3-D surface seismic survey. The VSP average velocities ranged from 800 to $1500 \mathrm{~m} / \mathrm{s}$ (2625 to $4921 \mathrm{ft} / \mathrm{s}$ ) for the area of interest.

The pseudo 3-D surface P-wave seismic reflection survey was designed using the GEDCO OMNI ${ }^{\circledR} 3-\mathrm{D}$ seismic design software. The survey was designed to image the top of lower clay unit. The depth of the lower clay unit at the P-reactor area site ranges from 21 to 37 $\mathrm{m}$ (69 to $121 \mathrm{ft}$ ) below land surface within our survey area of 34 by $170 \mathrm{~m}(558 \mathrm{ft})$. The pseudo 3-D CDP swath survey was acquired with the source line parallel to the receiver line. In this acquisition design, the shots were fired on one line, and the reflected seismic energy was recorded on the parallel receiver line creating a CDP swath midway between the source and receiver line (Stone, 1994; Cordsen et al., 1995; Rex et al., 2003).

From previous experience in acquiring and processing shallow seismic data at SRS in conjunction with the VSP data, the acquisition parameters were as follows: receiver and shot spacing of $1 \mathrm{~m}(3 \mathrm{ft})$, sample rate of $0.5 \mathrm{~ms}$, and record length of $500 \mathrm{~ms}$ (Table 1). In Figure 5, the red circles represent the receiver lines that are $2 \mathrm{~m}$ $(6 \mathrm{ft})$ apart, and the black circles represent the shot lines that are $2 \mathrm{~m}(6 \mathrm{ft})$ apart. An example of a receiver line is highlighted in light blue to indicate live receivers, with the star being the shot location. The ability to shoot the survey prior to field deployment allowed us to determine if we had enough fold (the higher the fold, the better the signal to noise ratio) at the target depth. An anticipated fold of 30 for the target depth of $35 \mathrm{~m} \mathrm{(115} \mathrm{ft)} \mathrm{below}$ land surface (Figure 5B) was calculated and collected based on the acquisition design described above. The field acquisition was performed with a Geometrics 120 channel StrataView ${ }^{\circledR}$ seismograph with $40 \mathrm{~Hz}$ geophones and consisted of pairs of one active source line and one receiver line. An accelerated weight drop (Digipulse Model 100AE) with 4 to 6 stacks per shot was used as the seismic source for a total of 2906 shots.

\section{DATA PROCESSING}

Data processing was focused on the enhancement of reflected energy within the vadose zone and below the water table. Also, efforts were made to preserve the seismic amplitude for attributes analysis. At SRS, because of the shallow, unconsolidated sediments, the generation of surface waves during seismic acquisition represents a major challenge. To attenuate the surface waves, various 2-D filtering techniques were applied, including frequency-wave-number (f-k) and bandpass filtering.

Processing the data set as a 3-D volume instead of a series of closely spaced 2-D lines allowed better interpretation of the target horizons, which are the lower clay and the sand directly above the clay. Processing as a volume allows the seismic data to be interpolated from crossline to crossline and from inline to inline. Then the data can be interpreted on each inline and crossline within the 3-D volume. Table 2 lists the processing steps completed using Landmark Graphics' ProMax ${ }^{\circledR}$ in generating the 3-D volume. The first and most critical step was creating the geometry from the field notes and acquisition design from the GEDCO OMNI ${ }^{\circledR} 3$-D software so that the data could be binned into a bin grid of 2 by $2 \mathrm{~m}$ ( 6 by $6 \mathrm{ft}$ ) totaling 1462 bins. The binning process merged the 17 individual 2-D lines into a volume with 17 inlines and 86 crosslines with 1462 CDPs (one CDP in each bin). After the field geometry was completed and loaded to the data set headers, the subsequent processing steps were used to generate the 3-D volume and enhance the reflectivity.

To increase the overall quality of the image, the data processing started with seismic trace editing to eliminate the noisy traces and to reverse the polarity of some traces. After trace editing, elevation statics were applied to account for topographic changes in the survey area. Elevations were collected for each receiver station of the survey using a TOPCON Total Station method. To account for amplitude loss caused by spherical spreading and attenuation, a spherical divergence correction was applied using a $1 /\left(\right.$ time $\left.\times[\text { velocity }]^{2}\right)$ function with a 0.0002 inelastic attenuation correction, a velocity function of $330 \mathrm{~m} / \mathrm{s}(1083 \mathrm{ft} / \mathrm{s})$ at $100 \mathrm{~ms}$ and $1500 \mathrm{~m} / \mathrm{s}$ $(4921 \mathrm{ft} / \mathrm{s})$ below $100 \mathrm{~ms}$, with a time-power constant 

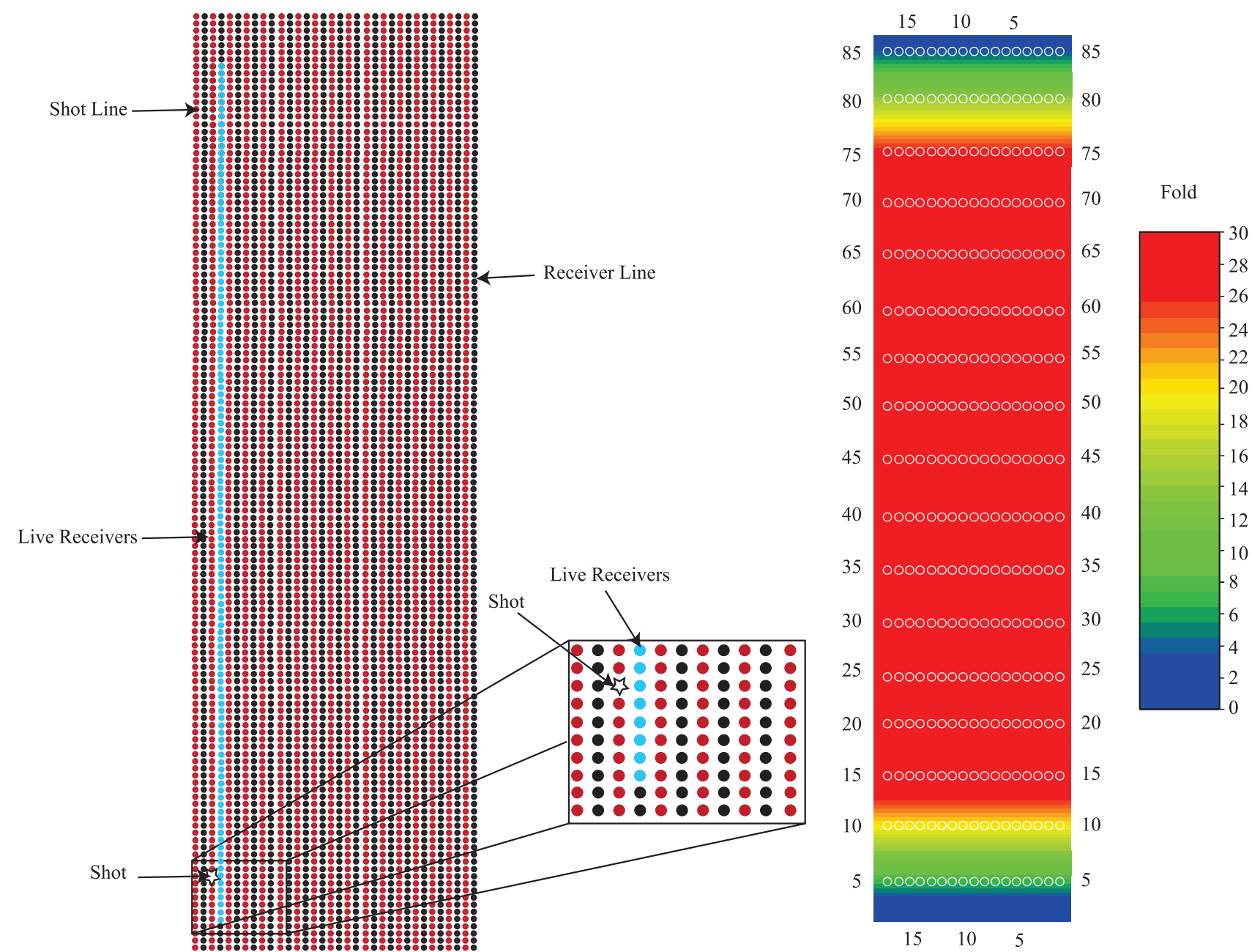

Figure 5. (A) Map showing the receiver and shot lines. (B) Map showing fold coverage, using the receiver and shot line configuration from panel $A$.

of 1.4. The next processing step involved predictive or spiking deconvolution using minimum phase spiking with an operator length of $20 \mathrm{~ms}$ and an operator white noise level of 0.1 .

To remove as much unwanted noise as possible, a zero-phase Ormsby bandpass filter was applied with a $60-\mathrm{Hz}$ notch for the overhead power lines and corner frequencies of 50-70-250-500 Hz. After the bandpass filter, an amplitude gain correction (automatic gain control) was applied using an operator window length of 20 ms. A progression of the processing steps can be seen in Figure 6, which shows a resulting shot gather with significantly improved signal-to-noise ratio.

An $\mathrm{f}-\mathrm{k}$ filter was used to remove coherent linear noise (Yilmaz, 1987), in the case of this data set, ground roll or surface waves. Figure 6 shows a shot gather before and after the application of the f-k filter. A significant improvement in the ground roll suppression can be noticed as the underlying reflections are substantially enhanced (Figure 6). After the rejecting polygon was designed in the $\mathrm{f}-\mathrm{k}$ domain, it was applied to the shot gathers before the velocity analysis.

After achieving an acceptable level of noise reduction in the prestack data, a velocity analysis was performed to obtain optimal stacking velocities. Because the stratigraphy and structure of the upper $40 \mathrm{~m}(131 \mathrm{ft})$ in the study area are fairly simple, a conventional normal move-out (NMO) stacking velocity analysis was used to obtain reliable root-mean-square velocities. As a guide for the velocity analysis, we used the VSP velocities. After velocity analysis (Figure 7), the resulting stacking velocities were smoothed and used to stack the data.

Subsequent processing was performed on the poststack data to further increase the signal-to-noise ratio and enhance the reflections. The residual statics was one such application that made a significant improvement in 
Table 2. Processing Steps Used in Generating the Final Stack

Description

Parameters

Geometry

Trace edits

Elevation statics

Spherical divergence

Deconvolution

Bandpass filter

Automatic gain control

f-k filter

Residual statics

Velocity analysis

Stack

f-xy deconvolution

Time and depth conversion
Defined using field notes, OMNI software, and loaded to headers

Eliminated bad or noisy traces and reversed trace with reverse polarity Applied from elevations of stations

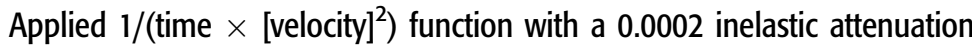

correction, a velocity function of $300 \mathrm{~m} / \mathrm{s}$ for $100 \mathrm{~ms}$ and $1500 \mathrm{~m} / \mathrm{s}$

$(4921 \mathrm{ft} / \mathrm{s})$ between $100 \mathrm{~ms}$, with a time-power constant of 1.4

Spiking or predictive deconvolution using minimum-phase spiking with

an operator length of $20 \mathrm{~ms}$ and an operator white noise level at 0.1

with a picked decon gate

Zero-phase Ormsby filter with a $60-\mathrm{Hz}$ notch and corner frequencies of

50-70-250-500 Hz

20-ms operator length

An arbitrary polygon used to reject noise

Applied residual statics

Analysis from shot gathers, constant velocity stacks with semblance plots

NMO-corrected CMP gathers added

Number of inlines and crosslines in filter was 3, the rate of adaptation

was 0.5 with starting and ending frequencies at 70 and $300 \mathrm{~Hz}$, respectively

Used VSP velocities to generate velocity profile picking velocities in the next iteration of velocity analysis. Once satisfied with the stacking velocities, we tested several coherency filters to improve the appearance of the targeted interfaces.

An f-xy deconvolution filter was used to enhance the coherency along reflections (Figure 8). This filter was used with a rate of adaptation 0.5 with starting and ending frequencies at 70 and $300 \mathrm{~Hz}$, respectively. Prior to the application of the $\mathrm{f}$-xy deconvolution filter, the reflections seen in the stacked data were not as pronounced and coherent horizontally as they were afterwards. After the f-xy deconvolution filter, the seismic volume was migrated with a velocity function derived from the VSP velocities. This same velocity function was used to convert the 3-D volume to depth.

\section{RESULTS}

After data acquisition and processing, the final result is a 3-D volume consisting of 86 crosslines and 17 inlines that enhance the geologic model for the site. The seismic data are shown in Figure 9 as a 34 by 170 by 150 m (558 by $492 \mathrm{ft}$ ) in depth volume with good reflectivity throughout. Because of the relatively lower fold coverage, the reflection coherency is lost at the edges of the volume as compared to that of the center zone. In Figure 9, two highly reflective areas between 20-60 and 120-150 m (66-197 and 394-492 ft) are observed. Between 20 and $60 \mathrm{~m} \mathrm{(66} \mathrm{and} 197 \mathrm{ft}$ ) is the area of interest consisting of the upper clay, middle sand, middle clay, lower sand, and lower clay units. These two areas show reflections that are for the most part subhorizontal. However, the reflections below the POS wells dip slightly. The dip becomes more extreme deeper in the volume, for example, note the reflections at 100 and $140 \mathrm{~m}$ (328 and $459 \mathrm{ft}$ ). The seismic volume was integrated with the geophysical well data in Kingdom ${ }^{\mathbb{R}}$ Suite and produced interpretable results with reference to our original hypothesis of adding supporting data to the conceptual model.

Based on the initial interpretations of cross section AA' (Figure 4) based on well and CPT information, the upper and middle clay layers appear to be continuous laterally across the study area. However, through a closer look, the thickness of the upper clay is thin compared to those of the other two clay layers, and the middle clay in the vicinity of POS-3 appears to be truncated, to almost disappear. The depth extension of the gamma data for POS-1 also has a limitation because of the shallower construction depth of this well, therefore the thickness of the middle clay is interpolated from the surrounding well data. Because of the presence of gravel deposits 


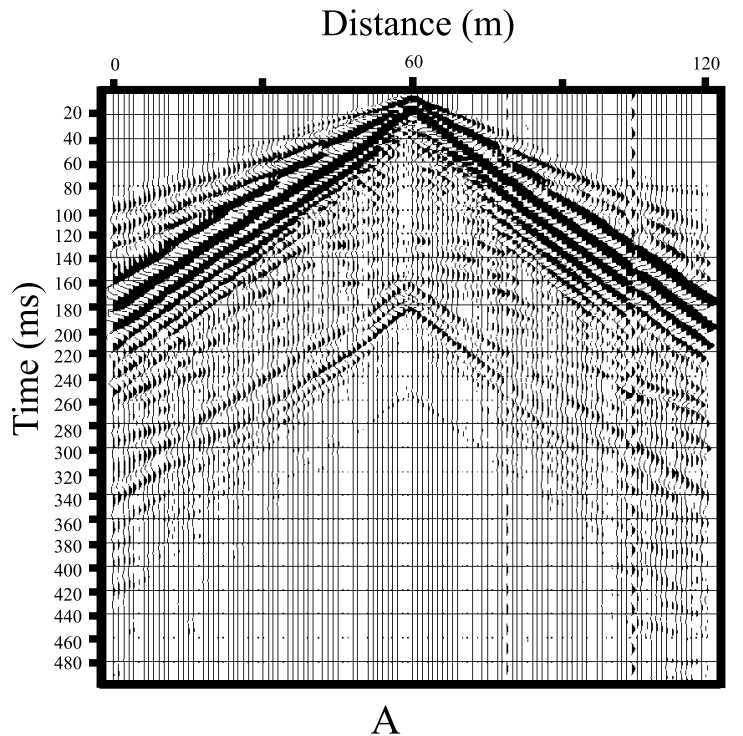

Distance $(\mathrm{m})$

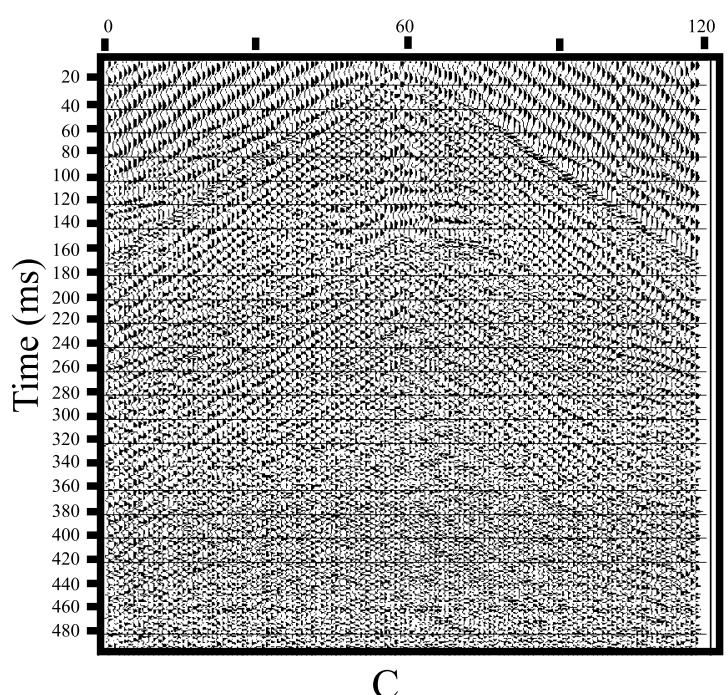

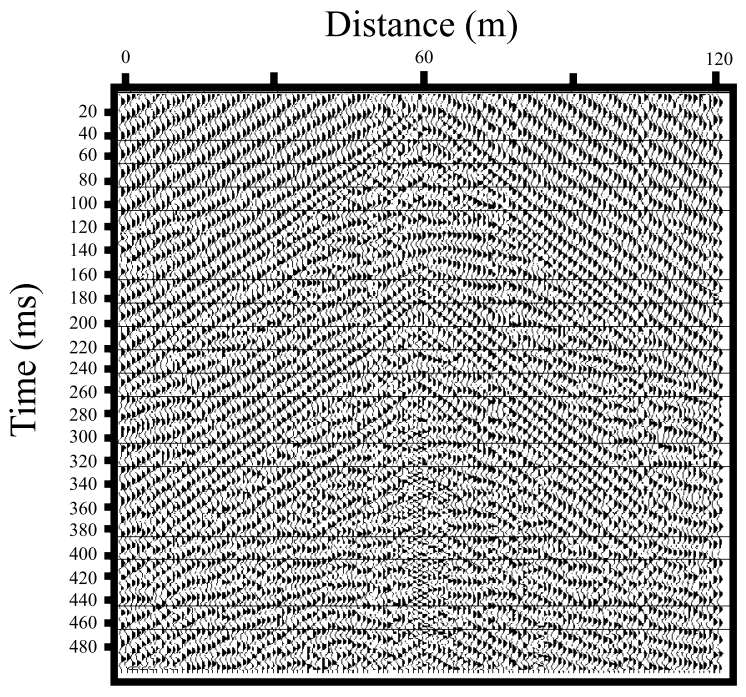

$\mathrm{B}$

Distance (m)

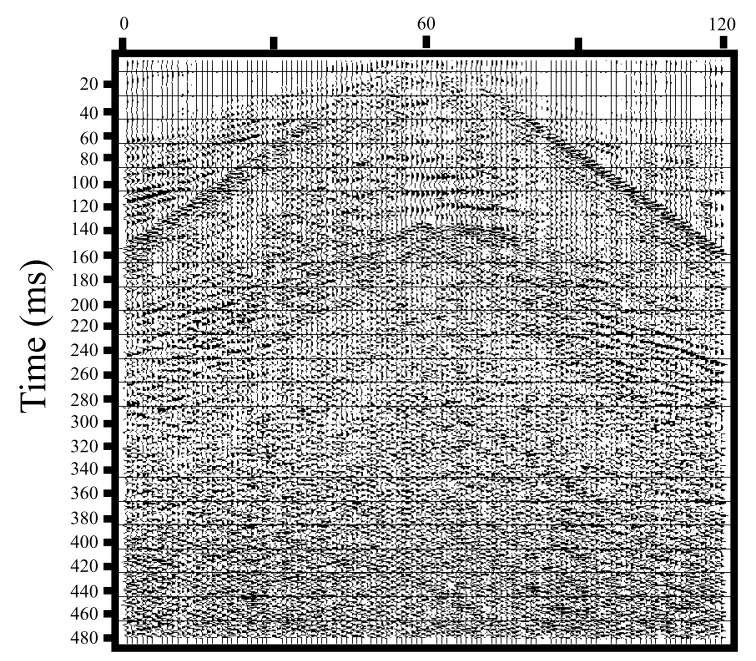

$\mathrm{D}$

Figure 6. (A) A sample shot gather (FFID 1790) showing raw data. (B) The same shot gather, but with spherical spreading correction, bandpass filter, and automatic gain control (AGC) applied. (C) The same as in panel B but with spiking deconvolution applied. (D) The same as in panel $\mathrm{C}$ but with the addition of the f-k filter. automatic gain control (AGC).

below and above the upper clay unit, along with the variable thicknesses of the upper and middle clay layers, one can interpret that the gamma logs are sensitive to the clay lenses that are present from a fluvial depositional environment as mentioned by Fallaw and Price (1995).

Figure 10 shows an image of crossline 27 from the 3-D survey oriented in the same direction as the geologic cross section $\mathrm{AA}^{\prime}$ in Figure 4. Crossline 27 shows a clipped part of the volume to a depth of $100 \mathrm{~m}(328 \mathrm{ft})$ with the position of the three POS wells, the gamma logs for POS-1 and -3 , and the clay horizons interpreted across the section. Crossline 27 shows the yellow hori- zon as the top of the lower clay and the green horizon as the top of the middle clay, which are the two units that contain the middle sand where the TCE plume is located. The blue horizon located on well POS-2 is where the top of the upper clay should be if it were present. Continuous throughout the section, the most welldefined reflection is the top of the lower clay unit, which is interpreted based on the thickness of this unit. The reflections attributed to the middle and lower clays at the POS wells correspond well with the gamma logs. The seismic crossline interpretation is essentially the same as the geologic cross section in Figure 4, with the 

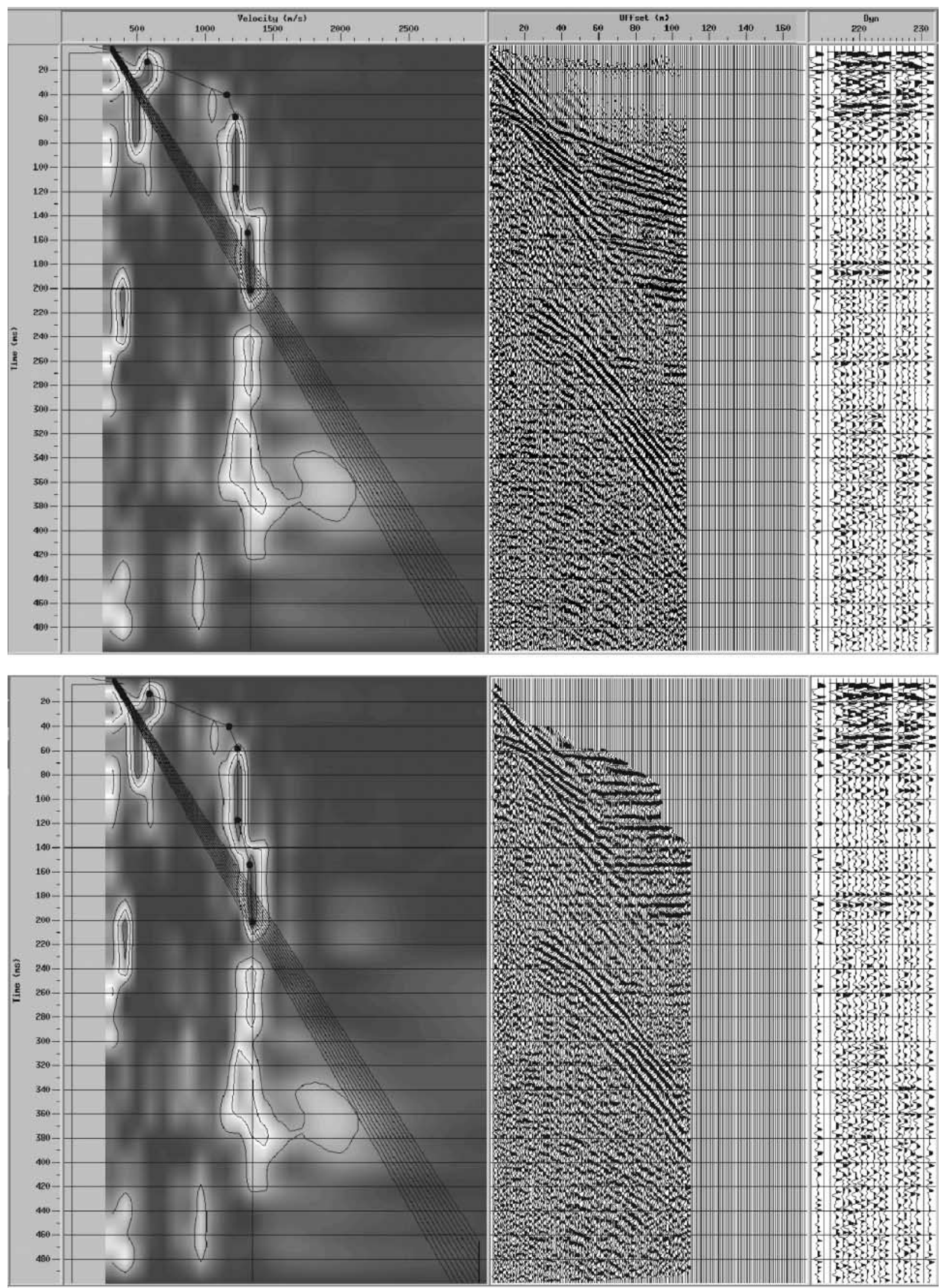

Figure 7. Velocity spectra and picks for the CDP supergather 222 (top) before and (bottom) after the NMO correction and 30\% stretch mute application. 


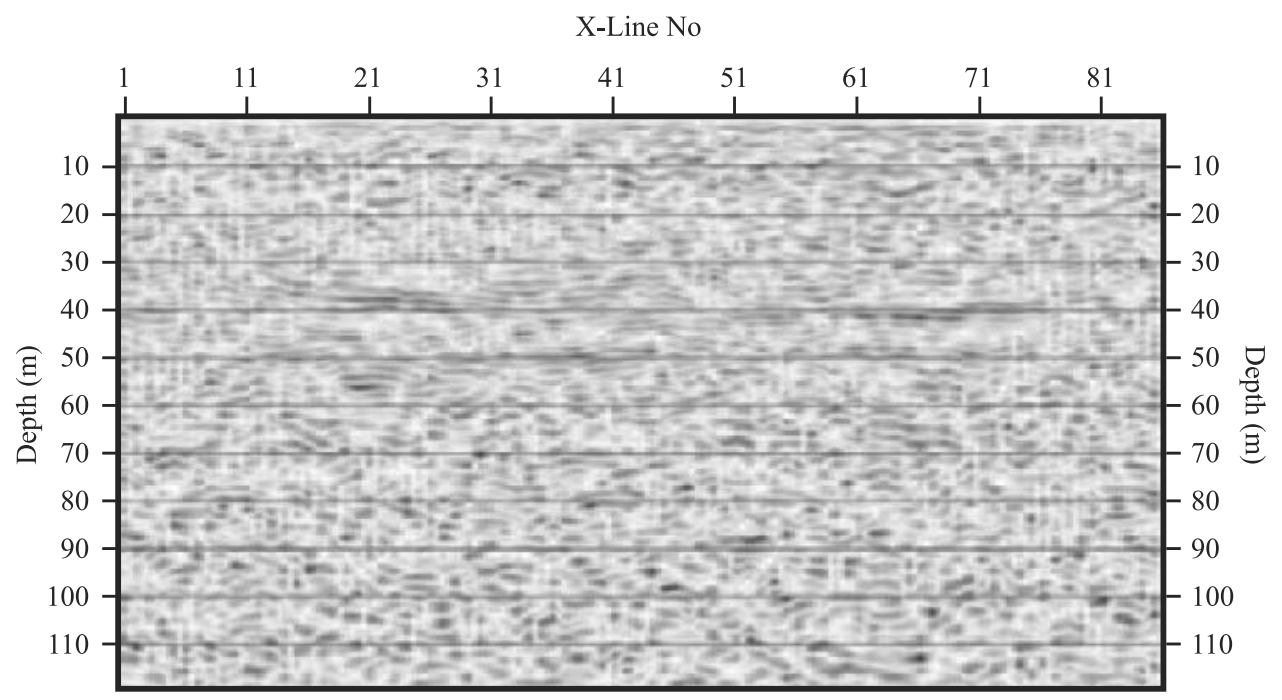

Figure 8. Stacked/inline 10 (top) without the f-xy deconvolution filter and (bottom) with the f-xy deconvolution filter. The reflections between 20 and $60 \mathrm{~m}$ (66 and $197 \mathrm{ft})$ show increased amplitudes and lateral coherency with the applied filter (bottom).

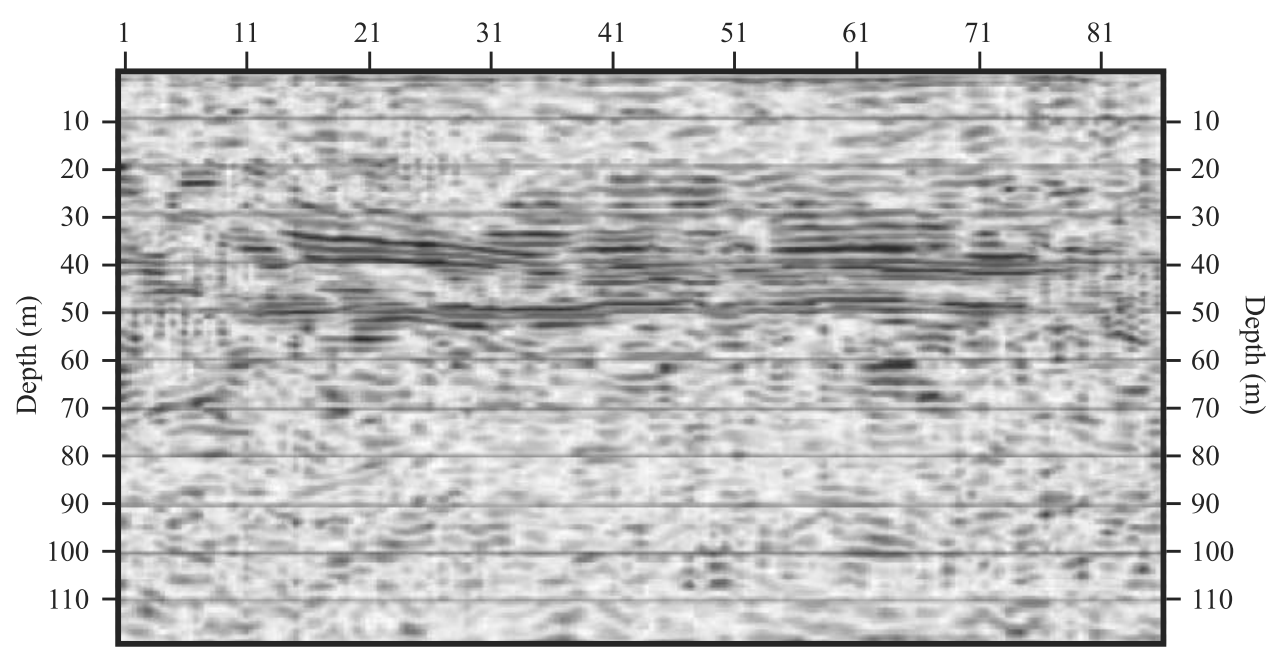

exception of the upper clay being absent on the seismic data.

Because the seismic data were processed as a volume, it allows the interpreter to analyze it in any arbitrary direction. Figure 11 is inline 10, which is perpendicular to crossline 27 shown in Figure 10. Starting from the southeastern end of the section near a depth of $10 \mathrm{~m}(33 \mathrm{ft})$ is a feature that is interpreted as a buried

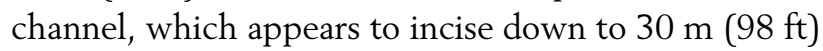
through the upper and middle clay units and possibly the lower clay unit. In addition, another channel is interpreted starting from roughly northwest of crossline 50 that also appears to incise the upper and middle clay units. Because the TCE and POS wells are located in the southeastern channel (red), this will be denoted as the primary channel and the channel interpreted toward the northwest (blue) will be denoted as the secondary channel.
Using ArcMap, we compared the depths of the channel complexes to the geometry of the plume inferred from the CPT and well data. Figure 12 shows a map view of the contoured channel complex depths on top of the TCE plume concentration map. Good well-data coverage of the TCE concentrations east of and within the seismic survey area allows for higher confidence in the plume concentration map. The deepest parts of the channel complex are near the POS wells. The plume source is located to the right in Figure 12 and flows from east to west on the map but narrows near the POS wells. Of note is a linear feature of the primary channel of depths $(22-25 \mathrm{~m})$ that trends north-south within the survey area in the vicinity of the POS wells. Although part of the linear trend may be caused by the depth conversion contouring in ArcMap, we believe that this feature is geologic because it is supported by the well data that illustrate (Figure 4) a difference in thickness of the 


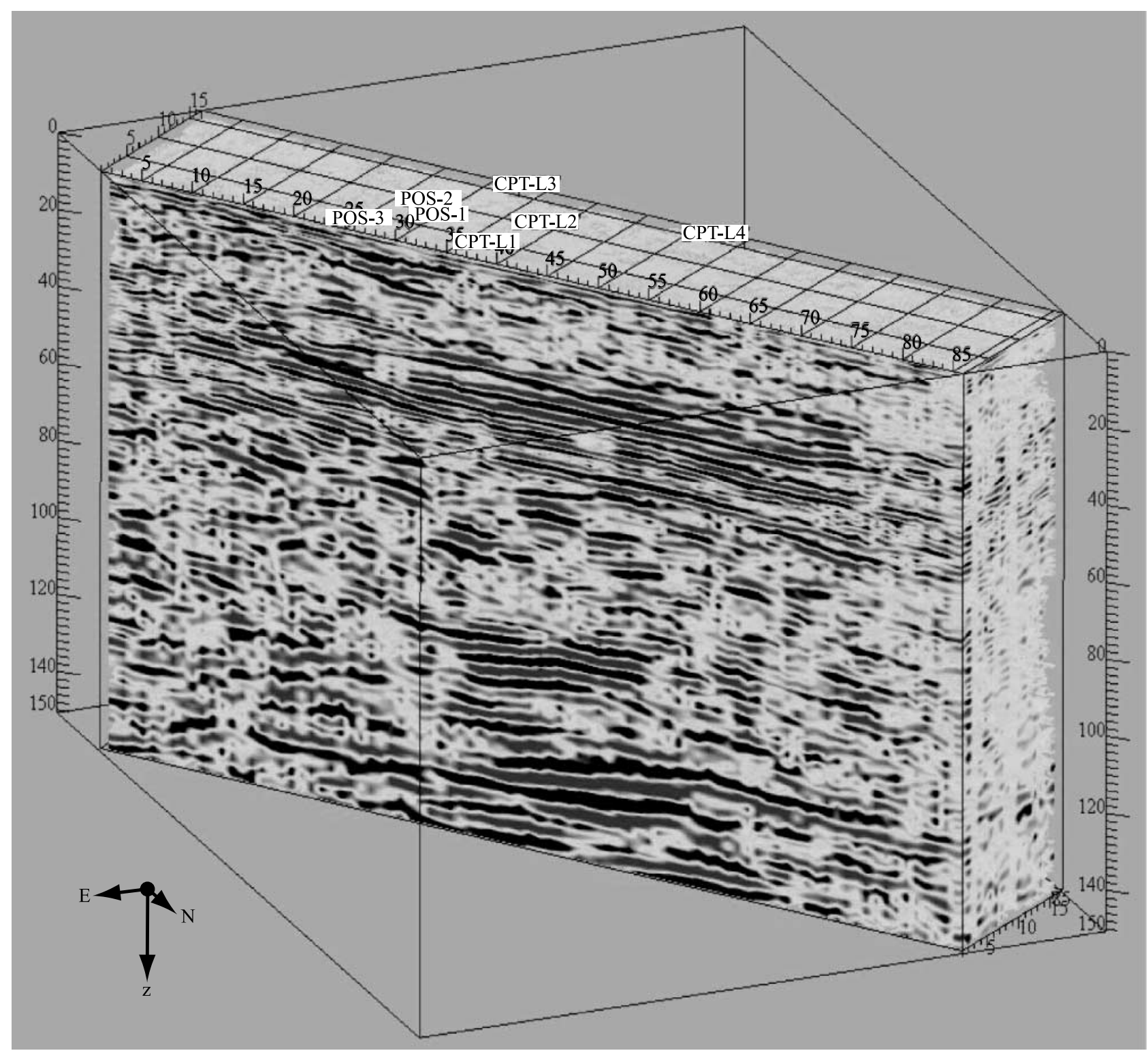

Figure 9. Final processed 3-D volume of the seismic reflection data. Volume dimensions are 170 by 34 by $150 \mathrm{~m}(558 \times 111 \times 492 \mathrm{ft})$. $\mathrm{CPT}=$ cone penetrometer. Position (POS) wells 1, 2, and 3 are also shown.

middle clay unit between POS-3 and CPT-L1. The narrowing of the plume within the seismic survey area corresponds to the linear feature of the deepest part of the primary channel.

\section{DISCUSSION}

Some of the significant results of this study are that (1) two new channel complexes, which are not present in the conceptual model, were identified in the upper $60 \mathrm{~m}$ of the section, and (2) the upper and middle clay units are not as continuous laterally as previously thought.
The presence of these two channels is confirmed by the location of the TCE plume below the middle clay near well POS-3 and the presence of gravel deposits in the core samples taken from the POS wells.

In Figure 12, the geometry of the primary channel has been transposed over the plume to investigate potential correlations between the shape of the plume and the presence of the primary channel. From the spatial relationship between the TCE plume and the mapped channels, the primary channel appears to act like a conduit for the TCE plume by causing a change (narrowing) in the shape of the plume. Looking at the hydrogeological aspects of this geometry, the plume's trajectory 

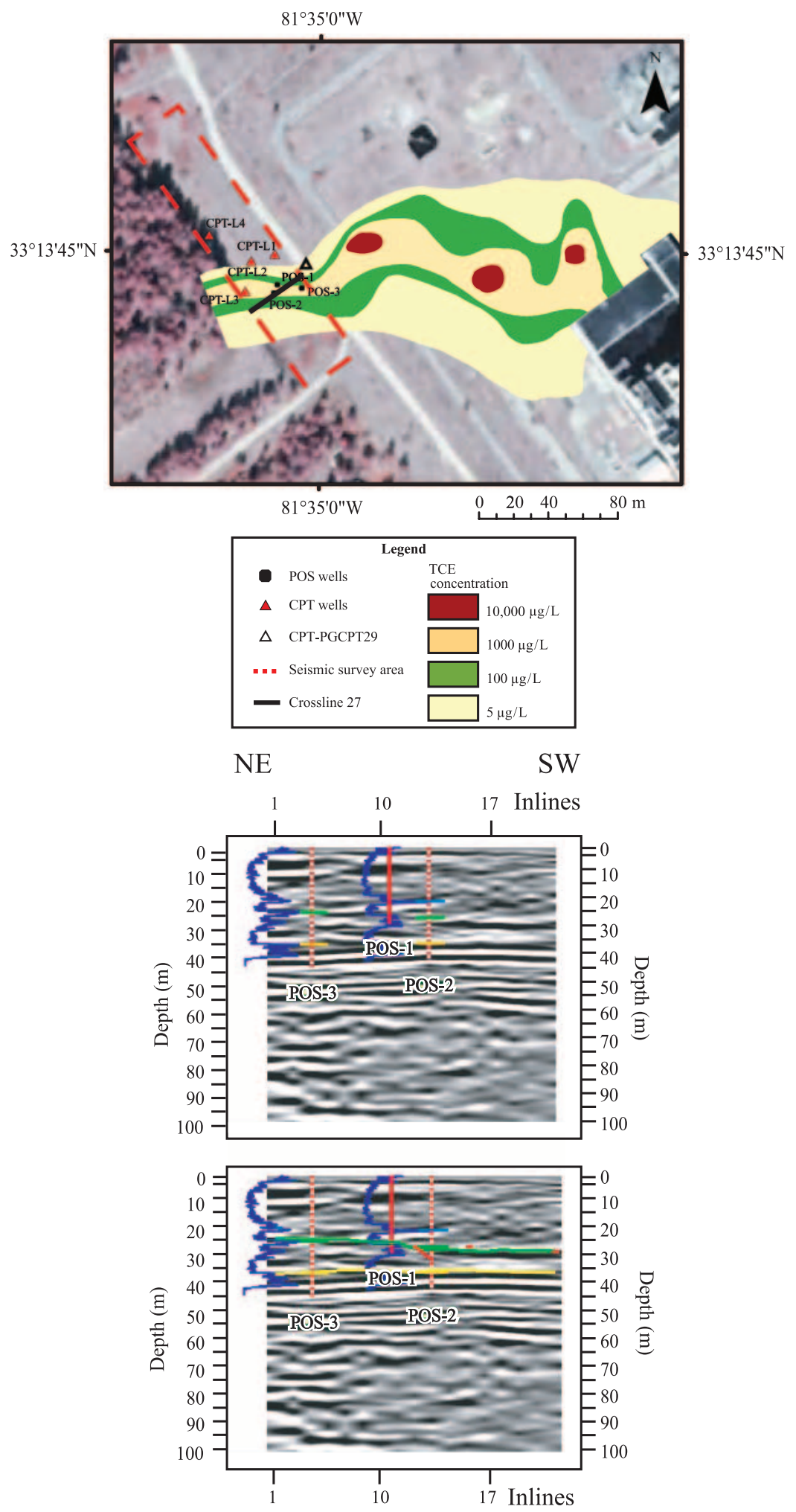

Legend

Gamma log

Top of upper clay

Top of middle clay

_ Top of lower clay
Figure 10. Crossline 27 is oriented in the same direction as Figure 3 . The yellow horizon is the top of the lower clay and the green horizon is the top of the middle clay. The blue horizon located on well POS-2 is where the top of the upper clay should be if it were present. CPT = cone penetrometer; $\mathrm{TCE}=$ trichloroethylene; $\mathrm{POS}=$ position well. 
Figure 11. Inline 10 is oriented perpendicular to crossline 27 . The yellow horizon is the top of the lower clay, the green horizon is the top of the middle clay, and the dark blue horizon is the top of the middle clay. The top of the upper clay appears to be absent on the seismic data. $\mathrm{CPT}=$ cone penetrometer; $\mathrm{TCE}=$ trichloroethylene; $\mathrm{POS}=$ position well.
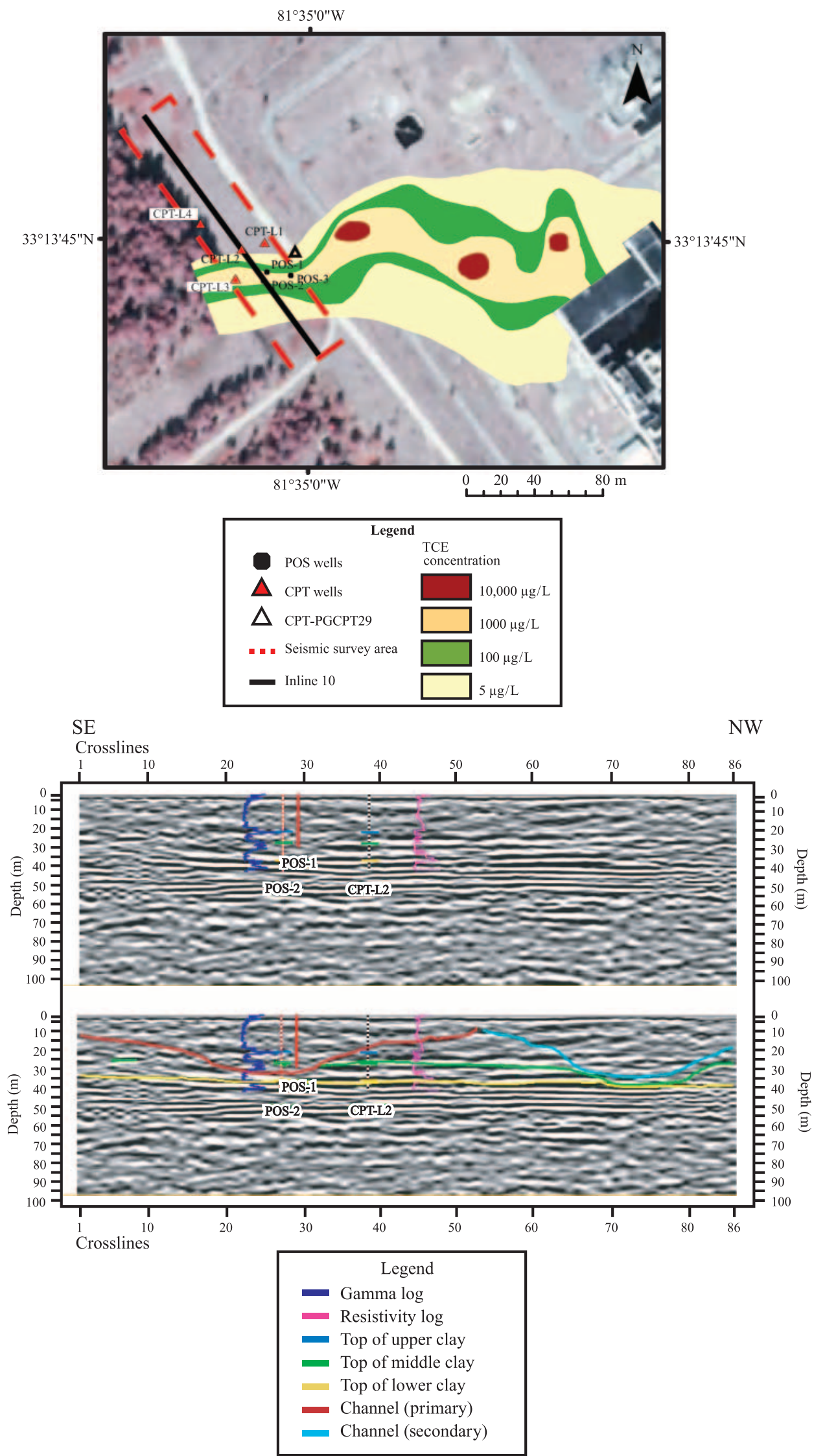


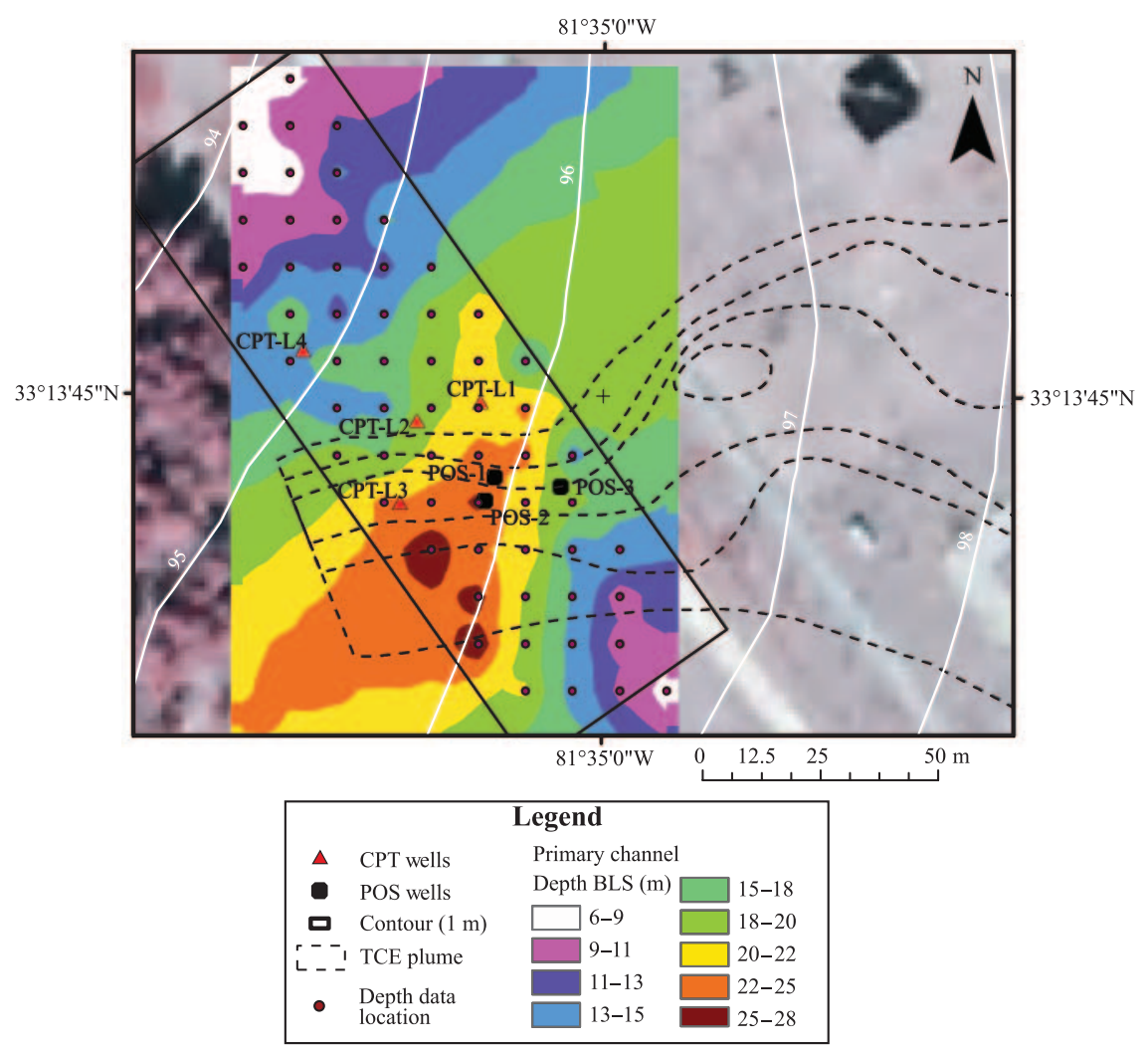

Figure 12. Isobaths of the two channel complexes gridded from the seismic data overlying the TCE concentration plume. The primary channel lies within the POS well cluster, whereas the secondary channel lies to the northwest. The deepest part of the primary channel lies to the east of POS-3 ranging from 22 to $28 \mathrm{~m}$ (72 to $92 \mathrm{ft}$ ) below land surface. CPT = cone penetrometer; TCE = trichloroethylene; POS = position well; BLS $=$ below the surface. appears to be controlled by the potentiometric surface whereas its shape could be controlled by the dispersion. Generally, with dispersion in typical porous media, the plume shape should become wider as it moves from the source point; however, here we see the opposite. A possible explanation could be that the channel is a conduit for the plume migration, which is consistent with the potentiometer data that indicate a convergence of groundwater flow (parallel to the primary channel) near the area northwest of the POS wells.

In the comparison between the initial conceptual model and the new conceptual model with the addition of the seismic data, some significant differences that also provide an explanation for the geometry of the plume migration are observed. The initial conceptual model was a simplified geologic characterization of the subsurface based on well data only. Although well data are important, they only provide point data, which are difficult to use when addressing a 3-D problem. The initial conceptual model consisted of continuous horizontal layering of the stratigraphy, whereas the seismic data show two channels that incise the horizontal layering.

In terms of further work with the existing 3-D data, we plan to derive seismic attributes, such as acoustic impedance, and see how they correlate with the geology and hydrogeology at the study area. The seismic attributes will be integrated with the other hydrogeophysical data and used in the modeling part of the project. We will also look at methods of improving our processing to improve the accuracy of any hydrogeophysical parameters estimated from the data such as porosity and hydraulic conductivity.

\section{CONCLUSIONS}

The P-reactor area at the SRS is located in South Carolina along the border with Georgia, consisting of 350-m-thick (1148-ft-thick) consolidated sands, clays, and gravels of the Atlantic coastal plain. The TCE was discovered at the site, and a conceptual model was created from previous works and well data. When characterizing a contaminated site, one has to develop a conceptual model to locate potential pathways for contaminant migration. These conceptual models generally are based on limited well data, tend to be simplistic, and in some cases do not properly represent the subsurface geology. A pseudo 3-D P-wave seismic reflection survey $(34 \times$ $170 \mathrm{~m} ; 111 \times 558 \mathrm{ft}$ ) was collected and processed in developing a more robust conceptual model for site characterization at the $\mathrm{P}$ area as part of a multiscale resolutions hydrogeophysical project. 
The results of the seismic survey indicate that at least two significant revisions of the conceptual model are needed, one related to the spatial continuity of the upper and middle clay units and the other one related to the discovery of two buried channels in the study area. The seismic data show not only that the upper and middle clay units are not continuous as previously thought, but that two buried channels that were not illustrated in the conceptual model are present. We were able to take the geometric information from the channel complexes from the seismic data and integrate it with the map view of the plume data for comparison. The comparison illustrated that the primary (southeast) channel correlates well with the shape of the plume near the well cluster, suggesting that the channel may influence the plume migration that is at odds with the general stratigraphy. Overall, the pseudo 3-D seismic data have enhanced our understanding of the subsurface geology at the $\mathrm{P}$ area by providing additional information to the conceptual model.

\section{REFERENCES CITED}

Aadland, R. K., J. A. Gellici, and P. A. Thayer, 1995, Hydrogeologic framework of west-central South Carolina: Report to the South Carolina Department of Natural Resources, Water Resource Division, 200 p.
Cordsen, A., J. W. Peirce, and M. Galbratith, 1995, Planning and operating a land 3-D seismic survey: Society of Exploration Geophysicists, Continuing Education Program, p. 5.1-5.34.

Fallaw, W. C., and V. Price, 1995, Stratigraphy of the Savannah River site and vicinity: Southeastern Geology, v. 35, no. 1, p. $21-58$.

Jean, G., J. M. Yarus, M. K. Harris, G. P. Flach, M. Millings, and F. Syms, 2002, 3-D geological modeling of the general separations area, Savannah River Site: Westinghouse Savannah River Company, p. 14-19.

Millings, M., K. Vangelas, and M. Harris, 2003, Source term determination for P-area reactor groundwater operable unit: Westinghouse Savannah River Company, Savannah River Site, Westinghouse Savannah River Company-TR-2003-00142, $1 \mathrm{p}$.

Reilly, T. E., and A. W. Harbaugh, 2004, Guidelines for evaluating ground-water flow, models: U.S. Geological Survey Scientific Investigations Report 2004-5038, Reston, Virginia, 1 p.

Rex, R., B. Goodway, C. Martin, and G. Uswak, 2003, The impact of azimuthal anisotropy AVO and petrophysical response in a fracture Wabamun gas reservoir (abs.): Canadian Society of Exploration Geophysicists/Canadian Society of Petroleum Geologists, p. 3-4.

Sheriff, R. F., and L. P. Geldart, 1995, Exploration seismology, 2d ed.: New York, Cambridge University Press, 244 p.

Stone, D. G., 1994, Designing seismic survey in two and three dimensions: Geophysical References: Tulsa, Oklahoma, Society of Exploration Geophysicists, no. 5, 141 p.

Wyatt, D. E., 2000, Savannah River site overview and general site information, in D. E. Wyatt and M. K. Harris, eds., Carolina Geological Society 2000 Field Trip Guidebook: Durham, North Carolina, Duke University, p. A9-A48.

Yilmaz, O., 1987, Seismic data processing: Investigations in geophysics, $2 \mathrm{~d}$ ed.: Tulsa, Oklahoma, Society of Exploration Geophysicist, $69 \mathrm{p}$. 